\title{
Dual Drainage of TAPVR-An Exquisite Connection
}

\author{
Amitabh Satsangi ${ }^{1}$ Dharmraj Singh ${ }^{1} \quad$ M. P. Hote ${ }^{1}$ \\ ${ }^{1}$ Department of Cardiothoracic and Vascular Surgery, All India \\ Institute of Medical Sciences, New Delhi, India52174175
}

\author{
Address for correspondence Amitabh Satsangi MS, MCh \\ CTVS, Department of Cardiothoracic and Vascular Surgery, All \\ India Institute of Medical Sciences, New Delhi, 10029, India \\ (e-mail: amoeba418@gmail.com).
}

\begin{abstract}
Keywords

- TAPVR

- Mixed Variant

- Dual Drainage

Dual drainage or double-connection total anomalous pulmonary venous return (TAPVR) is a rare variant in which all four pulmonary veins enter a common venous chamber that then drains into the systemic veins via two or more channels at the supracardiac, cardiac, or infra-cardiac levels. The traditional classification of total anomalous pulmonary venous connection (TAPVC) does not categorize dual drainage separately. We present a case of TAPVR with dual drainage in a 6-year-old child with a rare variety of connection.
\end{abstract}

\section{Introduction}

Dual drainage or double-connection total anomalous pulmonary venous return (TAPVR) is a rare variant in which all four pulmonary veins enter a common venous chamber that then drains into the systemic veins via two or more channels at the supracardiac, cardiac, or infracardiac levels. The traditional classification of total anomalous pulmonary venous connection (TAPVC) does not categorize dual drainage separately. ${ }^{1}$

We present a case of total anomalous pulmonary venous return with dual drainage.

\section{Case Report}

A 6-year-old child with central cyanosis, dyspnea on exertion, Ross class III, and failure to thrive underwent transthoracic echocardiography (-Figs. 1 and 2 ). The openings of the pulmonary veins into the left atrium (LA) could not be demonstrated, suggesting a possible diagnosis of TAPVR. The coronary sinus was also dilated, indicating a cardiac or mixed variant of TAPVR.

A cardiac computed tomography angiography (CTA) revealed all the pulmonary veins joining to form a common channel ( - Figs. 3 and $\mathbf{4}[\mathrm{A}, \mathrm{B}, \mathrm{C}]$ ) posterior to the LA. The common channel was seen to open into persistent left superior vena cava (LSVC): first, the LSVC opened into the coronary sinus into right atrium (RA); further, the LSVC opened into the right superior vena cava via the innominate vein. The said configuration constituted a rare mixed variant of TAPVR not described in the present classification system. Other associated defects included a large atrial septal defect (ASD) and small LA. The RA and right ventricle were (RV) dilated and there was no pulmonary venous obstruction.

\section{Discussion}

TAPVR develops when the primordial pulmonary vein fails to unite with the plexus of veins surrounding the lung buds. TAPVR is a rare congenital anomaly, corresponding to approximately $2 \%$ of all congenital heart defects. ${ }^{2}$

Double drainage of TAPVR is a rare variant of a mixed type TAPVR, which occurs when all the pulmonary veins form a confluence and then drain to both the coronary sinus and the left innominate vein. ${ }^{3,4}$ Recently, however, other variants of TAPVRs with double drainage have been reported. ${ }^{5}$ In our case, we reported all the four pulmonary veins draining into the common chamber, which opened into the persistent LSVC, having a dual drainage into the coronary sinus as well as the right superior vena cava via innominate vein. published online August 5, 2021
DOI https://doi.org/ $10.1055 / \mathrm{s}-0041-1732844$ ISSN 2457-0206 (c) 2021. Official Publication of The Simulation Society (TSS), accredited by International Society of Cardiovascular Ultrasound (ISCU).

article published by Thieme under the terms of the Creative Commons Attribution-NonDerivative-NonCommercial-License, permitting copying and reproduction so long as the original work is given appropriate credit. Contents may not be used for commercial purposes, or adapted, remixed, transformed or built upon. (https://creativecommons.org/licenses/by-nc-nd/4.0/). Thieme Medical and Scientific Publishers Pvt. Ltd. A-12, 2nd Floor, Sector 2, Noida-201301 UP, India 


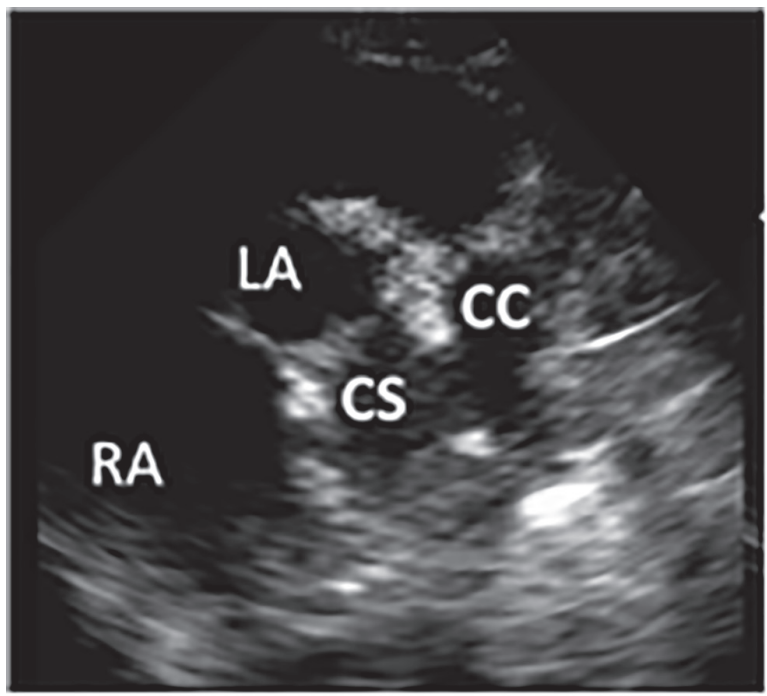

Fig. $12 \mathrm{D}$ Echo common chamber (CC) opening into coronary sinus (CS).

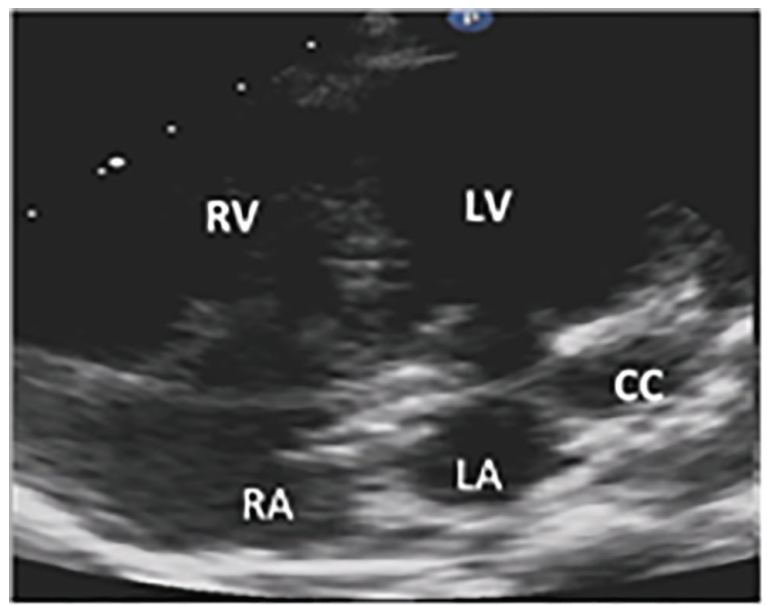

Fig. 2 2D Echo apical four-chamber view-small left atrial (LA) size, enlarged right atrium (RA), right ventricle (RV) and common chamber (CC).

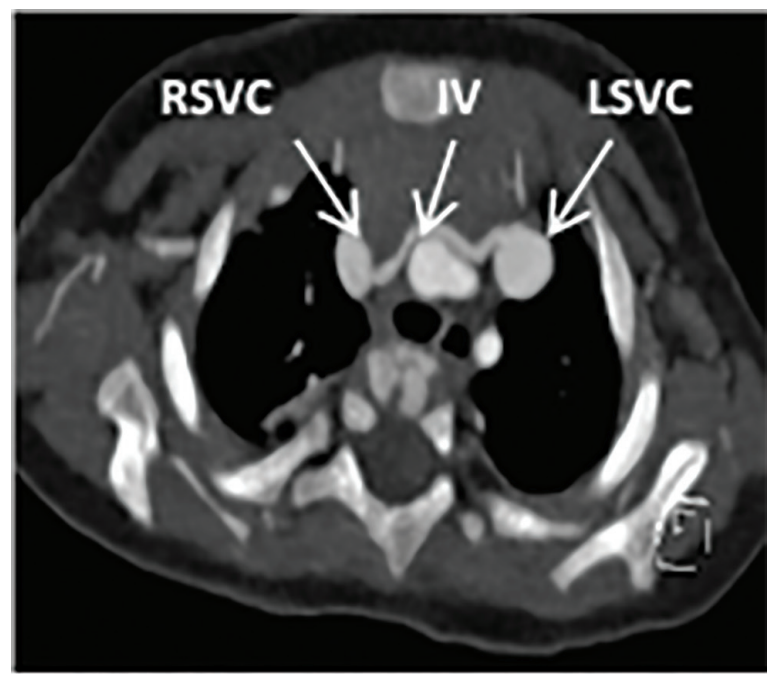

Fig. 3 CT angiography axial section-innominate vein (IV) connecting persistent left superior vena cava (LSVC) and right superior vena cava (RSVC).
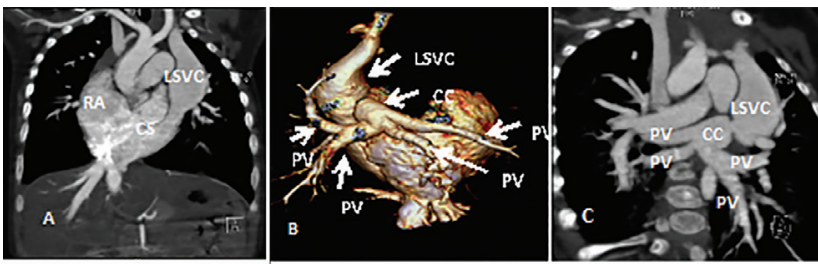

Fig. 4 CT cardiac angiography-(A) Persistent left superior vena cava (LSVC) opening via coronary sinus (CS) into right atrium (RA). (B) 3D-reconstructed, volume-rendered images from cardiac CT angiography-all four pulmonary veins (PVs) opening into common chamber (CC) which opens into LSVC. (C) All four PVs opening into CC which opens into LSVC.

Preoperative identification of TAPVR with double drainage has important surgical implications. Failure to address both the drainage of TAPVR may result in residual left-to-right shunting that requires further intervention and increases morbidity and mortality.

\section{Funding}

No funding source

\section{Ethical Approval}

Not applicable

\section{Human Rights}

Not applicable

\section{Statement of Informed CONSENT}

Written informed consent was obtained from the patient (s) for their anonymized information to be published in this article'

\section{Conflict of Interest}

None declared.

\section{References}

1 Craig JM, Darling RC, Rothney WB. Total pulmonary venous drainage into the right side of the heart; report of 17 autopsied cases not associated with other major cardiovascular anomalies. Lab Invest 1957;6(1):44-64

2 Bharati S, Lev M. Congenital anomalies of the pulmonary veins. Cardiovasc Clin 1973;5(1):23-41

3 Lee ML, Wang JK, Wu MH, Chu SH, Lue HC. Unusual form of total anomalous pulmonary venous connection with double drainage. Pediatr Cardiol 1995;16(6):301-303

4 Arciprete P, McKay R, Watson GH, Hamilton DI, Wilkinson JL, Arnold RM. Double connections in total anomalous pulmonary venous connection. J Thorac Cardiovasc Surg 1986;92(1):146-152

5 Tanabe S, Nakasato M, Suzuki $\mathrm{H}$, Ishikawa A, Fukasawa M, Hayasaka K. A new form of total anomalous pulmonary venous connection with double drainage. Pediatr Int 2000;42(4):369-371 